\title{
A EXPRESSÃO GRAMATICAL DA POLIDEZ EM TAPIRAPÉ
}

\author{
(The grammatical expression of politeness in tapirapé)
}

\author{
Walkíria Neiva Praça ${ }^{1}$ \\ Helena da Silva Guerra Vicente ${ }^{2}$ \\ (Universidade de Brasília - UnB)
}

\begin{abstract}
We argue in this paper that Tapirapé, an indigenous language of Mato Grosso State, Brazil, makes use of negative politeness strategies (Goffmann, 1959; Brown \& Levinson, 1987 [1978]), which can be observed through a break in person hierarchy rules $(1>2>3)$ commonly observed in TupiGuaraní languages (Monserrat \& Facó Soares, 1983). Our hypothesis is that such a break occurs in situations in which the speaker intends to mitigate his/her position of superiority over his/her listener.
\end{abstract}

Key-words: Tapirapé, person hierarchy, politeness, face.

\section{RESUMO}

Argumentamos, neste artigo, que o Tapirapé, língua indígena do estado de Mato Grosso, lança mão de estratégias de polidez negativa (Goffmann, 1959; Brown \& Levinson, 1987 [1978]), que se manifestam por meio de uma quebra na hierarquia de pessoa $(1>2>3)$ comumente observada em línguas do tronco Tupí-Guaraní (Monserrat \& Facó Soares, 1983). Nossa hipótese é a de que a quebra se dá justamente em situações nas quais ofalante procura minimizar uma posição de superioridade em relação à de seu interlocutor.

Palavras-chave: Tapirapé, hierarquia de pessoa, polidez, face.

1. Mestre e Doutora em Linguística, a autora é docente e pesquisadora do Departamento de Linguística, Português e Línguas Clássicas (LIP-UnB).

2. Docente e pesquisador do Departamento de Linguística, Português e Línguas Clássicas (LIP-UnB), onde atua em cursos da Graduação e da Pós-Graduação. A autora agradece o apoio concedido pela Fundação de Empreendimentos Científicos e Tecnológicos (FINATEC - edital 01/2010 - Participação em Eventos Científicos) e as contribuições do público presente no 5th International Symposium on Politeness, em Basel, Suíça, 2010. 


\section{Introdução}

O Tapirapé, bem como outras línguas indígenas da América do Sul, apresenta um fenômeno linguístico conhecido na literatura como "hierarquia de referência" ou "hierarquia de pessoa" (Monserrat \& Facó Soares, 1983), cuja ruptura, argumentamos, pode ser interpretada como uma estratégia de preservação da face (Goffmann, 1959; Brown \& Levinson, 1987 [1978]). Os verbos dessa língua, mesmo se transitivos, têm apenas uma posição de argumento, independentemente do número de participantes envolvidos no discurso. O preenchimento dessa posição é feito preferencialmente pela pessoa mais alta na hierarquia, que, no caso do Tapirapé, é $1>2>3$. Mesmo se a $2^{\mathrm{a}}$ ou a $3^{\mathrm{a}}$ pessoa for o Agente e a $1^{\text {a }}$, o Paciente, é a $1^{\text {a }}$ que estará assinalada no verbo. Notamos, contudo, que essa rigidez pode ser quebrada em nome do trabalho de face. Nossos dados mostram que a assimetria em uma interação pode, de modo generalizado, ser mitigada por meio da promoção do afixo de $2^{\mathrm{a}}$ pessoa à lacuna que seria ocupada pelo afixo de $1^{\text {a }}$ pessoa em situações nas quais o falante sente que pode constranger o ouvinte e, em consequência, a si mesmo. Assim, ao invés de dizer "Eu vou ajudar (você)", o falante de Tapirapé diria algo que poderia ser traduzido como "Você será ajudado (por mim)". Tal fenômeno nos leva a argumentar que estratégias de polidez negativas (Brown \& Levinson, 1987 [1978]) são fortemente observadas nessa língua.

O trabalho está estruturado da seguinte forma: na seção 2, apresentamos a literatura tradicional sobre os conceitos de polidez e face e, em seguida, uma abordagem que revisita essas noções; a seção 3, dividida em três subpartes, "A hierarquia de pessoa", "Sistema de marcadores de pessoa" e "Uma sequência", descreve o modo pelo qual a polidez está, pelo menos em parte, gramaticalizada na morfossintaxe da língua Tapirapé; a seção 4 traz as perspectivas da pesquisa sobre polidez e face de um modo geral e da nossa pesquisa, voltada especificamente para o estudo da expressão gramatical da polidez em Tapirapé. 


\section{O ritual da interação: polidez e face}

Nesta seção, apresentamos, em 2.1, a visão clássica das noções de polidez e face (Goffman, 1959; Brown \& Levinson, 1987 [1978]), para, em seguida, em 2.2, abordá-las à luz da literatura mais recente sobre o assunto (sobretudo O'Driscoll, 1996, 2008, 2010).

\subsection{Polidez e face: visões clássicas}

Os termos "polidez" e "face" costumam andar lado a lado, mas, uma forma de se conseguir ver as duas noções como complementares, porém, dissociáveis, é pensar que face é algo que um indivíduo tem; polidez é algo que um indivíduo faz (O’Driscoll, 2008). Em outras palavras, a polidez, em uma interação, é definida como o meio que empregamos para demonstrar estarmos conscientes da face do outro (Yule, 1996). O termo "face" foi introduzido pelo sociólogo canadense Ervin Goffman (1959) nos anos 50 a partir da expressão idiomática to lose face ("sentir-se humilhado, envergonhado, constrangido", ou, mais informalmente, "quebrar a cara", "ficar com cara de tacho", "ficar com a cara no chão") ${ }^{3}$ e está relacionado à auto-imagem pública que todo indivíduo possui.

A Teoria da Polidez, proposta por Brown \& Levinson (1987 [1978]), doravante B\&L, toma a noção de face como um pressuposto, e as extensões para o termo, isto é, "face positiva" e "face negativa", ${ }^{4}$ amplamente difundidas na literatura, foram cunhadas por esses autores com base na noção de Goffman e em termos usados por Durkheim, (positive and negative rites, "ritos positivos e negativos") em sua obra The Elementary Forms of Religious Life (1915, apud B\&L, 1987

3. Traduções sugeridas em Vicente \& Ramalho (2009).

4. As palavras "positiva" e "negativa" não significam, dentro desse modelo, "boa" ou "ruim”. Trata-se apenas de dois pólos opostos. Alguns autores, como, por exemplo, Scollon \& Scollon (1983, apud O’ DRISCOLL (1996)), preferem, ao invés de "polidez positiva" e "polidez negativa", os termos "polidez de solidariedade" e "polidez de deferência”, respectivamente. 
[1978]). Dentro desse modelo, portanto, todo indivíduo possui uma face positiva e uma face negativa, que correspondem, respectivamente, (i) à necessidade de pertencer a um determinado grupo e (ii) à necessidade de ser respeitado, e, mesmo, tratado com deferência. Os autores admitem a variação intercultural do conteúdo da face, mas argumentam a favor da universalidade do conhecimento mútuo das exigências da face como auto-imagem pública. Os seguintes exemplos em Yule (1996: 60) ilustram os dois tipos de face:

Excuse me, Mr Buckingham, but can I talk to you for a minute?

(1) a. 'Com licença, Mr Buckingham, mas posso falar com o senhor por um minuto?'

b. Hey, Bucky, got a minute?

'E aí, Bucky, posso falar um minutinho com você?'

Na primeira situação, temos alguém que demonstra - por meio da escolha de marcas linguísticas que denotam respeito e deferência - estar ciente da distância social entre ele e seu interlocutor. Na segunda situação, ao contrário, percebemos marcas que denotam camaradagem e intimidade. Diz-se, então, que, para cada situação, o falante está ciente das exigências de face (negativa, para o primeiro exemplo; positiva, para o segundo) de seu interlocutor.

B\&L se referem aos sujeitos de uma interação como MPs (Model Persons, "Pessoas-Modelo"), dividindo-os em S (speaker, "falante") e H (hearer, addressee, "ouvinte", "destinatário", "interlocutor"). O MP, de acordo com eles, corresponderia ao falante fluente e com vontade própria de uma língua natural, dotado de duas propriedades especiais: racionalidade e face. Os autores definem essas propriedades da seguinte maneira (B\&L, 1987 [1978]: 58):

By 'rationality' we mean something very specific - the availability to our MP of a precisely definable mode of reasoning from ends to the means that will achieve those ends. By 'face' we mean something quite specific again: our MP is endowed with two particular wants - roughly, 
the want to be unimpeded and the want to be approved of in certain respects. ${ }^{5}$

Assim, todas as Pessoas-Modelo, além de terem uma fase positiva e uma face negativa, seriam, também, agentes racionais, dotados da capacidade de escolher os meios para satisfazer determinado fim. Tendo isso estabelecido, a questão que se coloca é: De que maneira esse ser - o falante fluente de uma língua natural, com vontade própria, dotado de racionalidade e face - usa a linguagem? A resposta, de acordo com os autores, é: de maneira cooperativa. De um modo geral, parece haver um acordo tácito entre os participantes de uma interação no sentido de estarem cooperando um(s) com o(s) outro(s). Assim, a preservação da face do falante depende da preservação da face do ouvinte, e vice-versa. A esse respeito, Goffman (1955: 15) argumenta que:

Some practices will be primarily defensive and others primarily protective, although in general one may expect these two perspectives to be taken at the same time. In trying to save the face of others, the person must choose a tack that will not lead to loss of his own; in trying to save his own face, he must consider the loss of face that his action may entail for others ${ }^{6}$

Em suma, uma interação, como processo cooperativo que é, baseia-se no que B\&L chamam de "mútua vulnerabilidade da face".

5. Tradução livre: "Por 'racionalidade' entendemos algo bem específico - trata-se de uma maneira precisamente definida, disponível para a nossa Pessoa-Modelo, de raciocinar a partir da finalidade que quer atingir, a fim de estabelecer os meios pelos quais atingirá aquele fim. Por 'face' entendemos algo bastante específico também: nosso MP é dotado de duas necessidades particulares - grosso modo, a necessidade de ser/estar desimpedido e a necessidade de obter aprovação em certos aspectos".

6. Tradução livre: "Algumas práticas são prioritariamente defensivas e, outras, protetoras, embora, em geral, possamos esperar que essas duas perspectivas estejam simultaneamente presentes em uma interação. Ao tentar preservar a face do outro, uma pessoa deve escolher uma linha de ação que não acarrete a perda da própria face; ao tentar preservar a própria face, ela deve levar em consideração a perda da face que sua ação pode acarretar para os outros”. 
Toda interação, ainda de acordo com B\&L, constitui-se de atos que, intrinsecamente, ameaçam a face - positiva ou negativa, a do falante ou a do ouvinte. Por "ato" entenda-se tudo aquilo que se pode pretender realizar por meio de interações verbais ou não-verbais. Um ato ameaçador da face (FTA, face threatening act) é aquele que vai contra as necessidades ou exigências de face do falante ou do ouvinte. Tendo em mente, contudo, que toda interação se caracteriza como uma cooperação estabelecida entre as duas partes, se um ato ameaça a face do ouvinte, vai, potencialmente, também ameaçar a face do falante.

\subsection{Polidez e face revisitadas}

Desde que foi lançado, em 1978, o influente modelo de B\&L, ao mesmo tempo em que serviu e serve de embasamento teórico para inúmeros estudos sobre a polidez, é, por outro lado, criticado por outros no que tange à possibilidade de ser aplicado universalmente. A Watts (2005), por exemplo, causa estranheza o fato de um modelo que se auto-proclama "universal" ter conquistado tantos adeptos durante os anos 90 e os continue conquistando até os dias de hoje.

Neste artigo, adotamos o ponto de vista defendido por O’Driscoll (1996), segundo o qual as noções de face positiva e face negativa (B\&L, 1987[1978]) e, em consequência, as noções de polidez positiva e polidez negativa (B\&L, 1987[1978]), podem, sim, ser adotadas, desde que a elas sejam feitas algumas adaptações. $\mathrm{O}$ autor é bem-sucedido ao demonstrar que, ao contrário do que afirmam os críticos, os conceitos em questão podem, de fato, ser vistos como traços universais dos seres humanos e, mais ainda, podem ser ferramentas úteis na análise de dados interculturais. De acordo com ele, a inaplicabilidade do conceito a outras culturas seria aparente, sendo necessária apenas uma reelaboração - ou refinamento - de certos aspectos do modelo de polidez de B\&L a fim de legitimá-lo como intercultural. Nesse sentido, a única maneira de se evitar que a dualidade da face seja vista como um exemplo de etnocentrismo é 
reformulá-la a ponto de torná-la independente de qualquer cultura em particular. Assim, ao invés de conceitos primitivos, O’Driscoll argumenta serem a face positiva e a face negativa compostos derivados da combinação da face como conceito mais abrangente e da dualidade de necessidades (do original, wants dualism) que seriam intrínsecas a todos os seres humanos, a saber, por um lado, a necessidade de ser aceito pelo grupo e, por outro, a necessidade de se isolar.

(2) Face positiva e face negativa na perspectiva de O'Driscoll face + necessidades positivas $=$ face positiva face + necessidades negativas $=$ face negativa

Ambas as faces envolveriam o que o autor denomina "consciência background", já que ninguém sai por aí desejando e buscando a satisfação das faces positiva e negativa de modo consciente: They are simply wants which people are driven to satisfy (O'Driscoll, 1996: 19). ${ }^{7}$ Por outro lado, um terceiro reflexo da face, a "face cultural" (tradução livre para culture-specific face), envolveria o que O'Driscoll chama de "consciência foreground", 8 variando de uma cultura para outra. Para o autor, a origem da maior parte das críticas feitas ao modelo de $B \& L$ residiria justamente na pressuposição de que, sendo um "agente racional", ou "pessoa-modelo", o falante teria uma consciência da face do tipo foreground, e não background. Dessa maneira, os autores acabam criando a ilusão de que os constituintes da face devam ser entendidos como estando relacionados a valores sociais percebidos de modo consciente, sendo, portanto, "reivindicados" pelo indivíduo.

Estabelecidos os três reflexos da face (positiva, negativa e cultural) e a distinção entre consciência background e consciência foreground, fica fácil concluir que os constituintes das faces positiva e negativa não podem variar de cultura para cultura, por serem

7. Tradução livre: "Elas são simplesmente necessidades que as pessoas são levadas a satisfazer".

8. O autor baseia essa divisão nos conceitos de Schumacher (1972 apud O'DRISCOLL, 1996), consciousness e self-awareness, respectivamente. 
inerentes à condição humana. Em relação à face cultural, O’Driscoll argumenta que a polidez positiva e a polidez negativa podem servir como heurística para a elaboração de máximas para as mais diversas culturas, formalizadas a partir do que o autor chama de 'bundles' of positive/negative norms for a variety of situations. ${ }^{9}$ Por fim, sugere que os universais da polidez sejam examinados na mesma linha do que fez Greenberg (1966, apud O’Driscoll, 1996) em relação à sintaxe (c.f. Roberts, 1997, para um resumo das generalizações de Greenberg). ${ }^{10}$ Assim, poderíamos construir generalizações do tipo a culture which uses positive politeness in situation $A$ will also use it in situation $B$ (O’Driscoll, 1996: 30). ${ }^{11}$

\section{A expressão gramatical da polidez em Tapirapé}

Antes de passarmos à descrição, em 3.2, da expressão gramatical da polidez no Tapirapé, faz-se necessária a apresentação, em 3.1, de um fenômeno linguístico presente na maioria das línguas do tronco Tupí: a hierarquia de pessoa. Como vimos argumentando, a polidez negativa nessa língua pode manifestar-se por meio da quebra dessa hierarquia. Para ilustrar o fenômeno, trazemos, em 3.3, um registro que corresponde a uma interação entre falantes nativos do Tapirapé e uma falante de Tapirapé como segunda língua. Por meio dessa sequência, observa-se que um erro cometido pela falante não nativa é, a um só tempo, de ordem estrutural (morfossintática) e pragmática.

9. Tradução livre: "Feixes de normas positivas e negativas para uma variedade de situações".

10. Roberts (1997) descreve que Greenberg tomou como amostra trinta línguas de famílias diferentes e observou que, apesar de haver uma variação considerável na ordem das palavras, essa variação era estruturada no sentido de que certas propriedades sintáticas variavam de maneira sistemática. Por exemplo, línguas do tipo $\mathrm{V}$ (erbo) S (ujeito) $\mathrm{O}$ (bjeto) seriam sempre preposicionais; línguas do tipo SOV seriam sempre posposicionais.

11. Tradução livre: "Uma cultura que faz uso da polidez positiva em uma situação A também o fará em uma situação B”. 


\subsection{A hierarquia de pessoa}

A hierarquia de pessoa é uma subespécie de hierarquia referencial proposta por Foley (1976; c.f. também Zwicky, 1977). Segundo esse autor, os sintagmas nominais possuem referencialidade inerente e se hierarquizam na estrutura da oração. A marcação dessa hierarquização pode ser realizada de diferentes maneiras pelas línguas, variando desde ordem de palavra, marcação de caso e codificação de pessoa. Desse modo, Foley (1976) propõe a existência de uma hierarquia referencial universal $1>2>3$ estruturada da seguinte maneira:

(3) Hierarquia referencial universal (Foley, 1976)

Falante $>$ ouvinte $>$ nome próprio (humano) $>$ nome comum (humano) $>$ animado $>$ inanimado

Segundo Queixalós (2006, c.p.), a hierarquia referencial é um dos componentes do gradiente de saliência, que se baseia na organização egocêntrica da experiência humana. Sua incidência na estrutura das construções transitivas constitui uma das claras manifestações dessa organização. Assim sendo, a hierarquia de pessoa organiza as pessoas do discurso, colocando os participantes dos atos de fala da zona intralocutiva - primeira e segunda pessoa - acima dos participantes da zona extralocutiva - terceira pessoa, ou a "nãopessoa" (Benveniste, 1991) - e depois posicionando, dentro da zona intralocutiva, o falante acima do ouvinte.

A hipótese de Praça (2007) é a de que a hierarquia de pessoa no Tapirapé é condicionada por fatores semânticos imbricados a fatores pragmáticos. A codificação de pessoa é condicionada pelas formas de interação social entre os falantes. A primeira pessoa é hierarquicamente superior às demais, mas, se, na zona intralocutiva, houver a possibilidade de um enfrentamento entre a primeira pessoa "eu" (falante) e a segunda pessoa "você" (ouvinte) (a partir de agora representada como $1 \rightarrow 2$ ), ocorrerá uma ruptura na hierarquia natural de pessoa $(1>2)$, que passará a $(2>1)$. Essa ruptura é decorrente da concomitância entre a hierarquização dos papeis semânticos "agente" e 
"paciente" e a codificação de primeira e segunda pessoa, que atenua o confronto na zona intralocutiva. Argumentaremos, pois, que a ruptura da cadeia hierárquica $(1>2)$ se dá em consequência de regras sociais de polidez, que suavizam o enfrentamento entre o falante e o ouvinte. Por enfrentamento, entendemos as situações em que ficaria patente algum tipo de superioridade do falante em relação ao ouvinte, como, por exemplo, uma situação em que o ouvinte ficaria "devendo um favor" ao falante ${ }^{12}$ (c.f. (4a) abaixo) ou na qual haveria uma assimetria de poder ou de força do falante em relação ao ouvinte (c.f. (4b) abaixo).

A fim de mitigar $1 \rightarrow 2$, então, seriam acrescentados aos verbos prefixos - \{ara- $\}$ e $\{$ ãpa- $\}$ - que fazem referência ao objeto, indicando que o paciente de segunda pessoa tem proeminência em relação ao agente de primeira pessoa. O prefixo $\{$ ara- $\}$ ocorre quando o agente é de primeira pessoa singular ou primeira exclusiva e o paciente é de segunda singular, como se vê em (2a); o prefixo \{ãpa-\}, por sua vez, ocorre quando o agente é de primeira pessoa do singular e o paciente, de segunda do plural, como se vê em (2b):
a.
ara-pyro ekwe we-a-wo 'ãwãxi- $\varnothing \quad \varnothing$-pyyk-a 2sg.IV-ajudar F.IMI 1sg.III-ir-GER milho-REFER 3.II- pegar-GER
"irei ajudar você a pegar o milho (lit: você será ajudado por mim a pegar o milho)"
b. ie- $\varnothing$ ãpa-nop $\tilde{y}$
1sg-REFER 2plIV-bater
"eu bato em vocês (lit: vocês serão batidos por mim)"13

Esse tipo de ruptura na hierarquia de pessoa é também verificado em outras línguas da família Tupí-Guaraní. Segundo Monserrat \& Facó Soares (1983: 181), a quebra da hierarquia de pessoa ocorre "por competição semântica entre os referentes de primeira e segunda

12. B \& L (1987 [1978]) referem-se à preocupação, por parte do falante, de livrar o ouvinte de qualquer tipo de dívida que possam ter em relação àquele, em sua estratégia de polidez negativa de número 10 (p. 210).

13. Apesar de as traduções literais estarem na voz passiva, observe-se, pelas glosas, que as sentenças originais no Tapirapé não se encontram nessa estrutura. 
pessoas, na relação específica sujeito "eu"/objeto "você. A contribuição de nosso trabalho é argumentar no sentido de que essa quebra, gramaticalizada na língua, ocorre em prol da manutenção da face negativa do ouvinte. A seguir, apresentamos o sistema de marcadores de pessoa do Tapirapé, enfatizando os das séries I e IV, já que esses serão relevantes para a nossa argumentação de que haveria um tipo de gramaticalização da polidez nessa língua.

\subsection{Sistema de marcadores de pessoa}

Os marcadores de pessoa são onipresentes no Tapirapé. São obrigatórios nos verbos e ocorrem nos nomes relativos ${ }^{14} \mathrm{e}$ autônomos e nas posposições. Dividem-se em seis marcas, sendo três para a primeira pessoa, duas para a segunda pessoa e uma para a terceira pessoa, e em quatro paradigmas denominados "Séries". O Quadro 1 a seguir apresenta os marcadores de pessoa do Tapirapé15:

\section{Quadro 1: Marcadores de pessoa do Tapirapé}

\begin{tabular}{|c|c|c|c|c|}
\hline & Série I & Série II & Série III & Série IV \\
\hline $1 \mathrm{sg}$ & ã- & xe & we- $\sim$ wex- & \\
\hline 1incl & xi- & xane & xere- $\sim$ xerex- & \\
\hline 1excl & ara- & are & ara- $\sim$ arax- & \\
\hline $2 s g$ & ere- & ne & e- $\sim$ ex- & ara- $(1 \mathrm{sg}$ ou $1 \mathrm{excl} \rightarrow 2 \mathrm{sg})$ \\
\hline $2 \mathrm{pl}$ & pe- & pe & pexe- $\sim$ pexex- & ãpa-(1sg $\rightarrow 2 \mathrm{pl})$ \\
\hline 3 & a- & \multicolumn{2}{|c|}{$\mathrm{i}-\sim \varnothing-\sim \mathrm{t}^{16} \mathbf{C}_{-} \sim \mathrm{h}^{17}$} & a- $\sim$ w- \\
\hline
\end{tabular}

14. Os nomes relativos são assim chamados por manterem uma relação de "dependência" com uma expressão referencial, cuja presença é obrigatória.

15. O sistema pessoal do Tapirapé é tipicamente de línguas Tupí-Guaraní e se mostra bem conservador, mantendo praticamente as mesmas formas reconstruídas por Jensen (1999: 147) para o Proto-Tupí-Guaraní.

16. Em geral, esse prefixo indica uma terceira pessoa humana e indeterminada.

17. Esse prefixo só ocorre em temas monossilábicos começados por vogal. 
Os marcadores de pessoa das Séries I, III e IV são prefixos não-acentuados, ao passo que os da Série II, exceto o da terceira pessoa, são pronomes clíticos também não-acentuados, mas que podem receber acento em determinados $\operatorname{casos}^{18}$. A terceira pessoa dessa Série é manifesta por meio de prefixos, como nas demais Séries. Todos os morfemas das quatro séries estão fonologicamente ligados a temas e não ocorrem como núcleos de sintagma, mas apenas como modificadores. $\mathrm{O}$ sistema referente às pessoas intralocutivas distingue singular/plural, sendo que na primeira pessoa do plural é feita a distinção de inclusão e exclusão do interlocutor, ou seja, a primeira pessoa do plural inclusiva e a exclusiva. Entretanto, a terceira pessoa, a “não-pessoa”, conforme Benveniste (1991: 251), não marca diferença de número, gênero e classe, noções inferidas pelo contexto.

As formas das Séries I e IV são exclusivas de verbos ativos. Os verbos intransitivos ativos são identificados por se flexionarem exclusivamente com o paradigma de prefixos da Série I e por possuírem apenas um participante único.

$\begin{array}{llll}\text { ã-yj } & \text { rãka } & \tilde{a} \text { ãẽ } & \text { nã=xe=r-ãkwãr-i } \\ \text { 1sg.I-correr } & \text { PAS.REC } & \text { CD } & \text { não=1sg.II=R-escorregar-NEG } \\ \text { "corri e não escorreguei”" } & & \end{array}$

Os verbos transitivos diferenciam-se morfossintaticamente dos intransitivos ativos por se flexionarem com os paradigmas das Séries I, II e IV. A marcação dessas Séries não ocorre simultaneamente, uma vez que, independentemente da valência verbal, só há uma vaga morfológica no verbo, e isso quer dizer que somente um participante é codificado. ${ }^{19}$ Assim, os prefixos da Série I marcam o Agente (exemplos (6) e (7)), ao passo que os marcadores da Série II, o Paciente ${ }^{20}$ (exemplos (8) e (9)).

18. Em geral, os clíticos da Série II recebem acento quando complemento da posposição we (dativo).

19. Nota-se, por meio dos exemplos, que todos os participantes estão presentes na oração sob a forma de expressões referenciais. No verbo, porém, somente um dos participantes será codificado.

20. Os termos Agente e Paciente estão sendo usados prototipicamente. 
(6)
xãwãr-a
a-o'o
xe=r-eymãw-a
cachorro-REFER
3.I-morder
1SG.II=R-animal.doméstico-REFER

"o cachorro mordeu minhas galinhas"

(7) ã'ẽ ekwe

a-xokã

CD F.IMI

3.I-matar

"então (meu pai) vai matá-lo"

(8) ãpĩ korinãka'i-ø

$\mathbf{x e}=\boldsymbol{\varnothing}$-mook

mamãe

Korinãka'i-REFER 1 SG.II=R-molhar

"mamãe, Korinãka'i me molhou"

(9)
veva-ø
ne $=\mathbf{r}-\mathbf{a r} \tilde{\mathbf{o}}$
a-ka-wo ka-pe
Veva-REFER
$2 \mathrm{SG} . \mathrm{II}=\mathrm{R}$-esperar
3.III-esperar-GER roça-LOC
"a Veva está esperando você na roça"

Os prefixos da série IV, por sua vez, fazem referência ao objeto, indicando que o Paciente de segunda pessoa tem proeminência em relação ao Agente de primeira pessoa. $O$ prefixo $\{$ ara- $\}$ ocorre quando o Agente é de primeira pessoa singular ou primeira exclusiva e o Paciente é de segunda singular ( $1 \mathrm{sg}$ ou $1 \mathrm{excl} \rightarrow 2 \mathrm{sg}$ ), conforme visto em (4a), aqui retomado como (10). A seu turno, o prefixo \{ãpa-\} ocorre quando o Agente é de primeira pessoa do singular e o Paciente de segunda do plural $(1 \mathrm{sg} \rightarrow 2 \mathrm{pl})$, conforme visto em $(4 \mathrm{~b})$, retomado como (11):

$$
\begin{aligned}
& \text { ara-pyro ekwe we-a-wo 'ãwãxi-ø ø-pyyk-a } \\
& \text { 2sg.IV-ajudar F.IMI 1sg.III-ir-GER milho-REFER 3.II-pegar-GER } \\
& \text { "irei ajudar você a pegar o milho (lit: você será ajudado por mim a pegar o milho)" }
\end{aligned}
$$

Em Tapirapé, não há outra estrutura morfossintática para expressar referência à segunda pessoa na configuração $(1 \rightarrow 2)$. Os prefixos $\{$ ãpa- $\}$ 
e \{ara- $\}$ compõem um paradigma especial - Série IV - e são usados exclusivamente nessa configuração. Como demonstrado, esses prefixos assinalam uma proeminência do paciente (segunda pessoa) em relação ao agente (primeira pessoa), o que, conforme argumentamos, trata-se de uma gramaticalização da polidez negativa nessa língua. Mesmo sendo a primeira pessoa hierarquicamente superior à segunda e à terceira pessoas $(1>2>3)$, observa-se que nas configurações $(2 \rightarrow 1)$ ou $(3 \rightarrow 1)$, exemplos (12) e (13) respectivamente, não há uma série de prefixos especial para marcar a proeminência da primeira pessoa na função de objeto em relação a outras pessoas do discurso.

$\begin{array}{ll}\mathbf{x e}=\varnothing-\mathrm{ma} \text { ' } & \text { xepe } \\ \text { 1sg.II=R-ensinar } & 2 \mathrm{sg} \rightarrow 1 \mathrm{sg} \\ \text { "você me ensina" } & \end{array}$

$\begin{array}{llll}\text { kã'ã-pe } & \text { rãka } & \tilde{a} \text { '̃ }=\text { =ga- } \varnothing & \text { are= }=\text {-nopỹ } \\ \text { mata-loc } & \text { pas.rec } & \text { dem=sg-refer } & \text { 1 excl.II-r-bater } \\ \text { “ontem na mata ele nos bateu” } & & \end{array}$

Como se pode observar, nesses exemplos são utilizados os prefixos $\{$ xe- $\}$ e $\{$ are- $\}$ da série II, usados também em orações subordinadas, marcando tanto o sujeito de verbos intransitivos ativos quando o objeto de transitivos, em verbos descritivos, em posposições bem com no nome, marcando seu possuidor.

\subsection{Uma sequência}

A seguir, tomando por base os desenvolvimentos mais recentes da teoria de polidez (c.f. Kádár, 2009) de que somente diálogos inseridos em sequências longas nos possibilitam construir um quadro real das negociações da (im)polidez, apresentamos um excerto dos registros de Praça, de um dos períodos (maio de 2004) em que realizou trabalho de campo junto aos Tapirapé da aldeia Urubu Branco, em Mato Grosso. $\mathrm{O}$ excerto ilustra a consciência (mesmo que background - ou "préconsciente" - de acordo com O’Driscoll,1996) que o falante tem da 
necessidade de ter os seus desejos de face preservados. De acordo com a hipótese que vimos defendendo até agora, boa parte da negociação da face é realizada por meio da quebra da rígida hierarquia de pessoa observada nas línguas Tupí como um todo.

(14) Uma sequência: registro de Praça (aldeia Urubu Branco-MT, maio de 2004)

Língua: Tapirapé

Interação entre dois falantes nativos do Tapirapé e uma falante do português: - K1 Tapirapé, criança do sexo masculino, 3 anos, monolíngue em Tapirapé. - K2 Tapirapé, mãe de K1, 28 anos, bilingue Tapirapé e português, sendo o português utilizado nas interações com os não-índios. Aprendeu o português aos 10 anos de idade, aproximadamente, quando este lhe foi ensinado na escola.

- WNP, falante nativa do português.

Apenas a primeira vez que fui aos Tapirapé, em julho-agosto de 1997, aldeia Majtyritãwa, fiquei em uma casa sem a companhia de uma família Tapirapé. A partir de fevereiro de 1998, sempre fiquei hospedada na casa deles, principalmente em companhia do casal $W$ e K2, muito gentil e amigo, e dos filhos, X1, X2, M1 e M2. Sempre tive laços afetivos com eles, especialmente com K1, que era chamado carinhosamente, de Namĩ (denominação de idade). Ele me via como um membro da família, e eu tinha por ele uma atenção toda especial. Ao amanhecer, ele me acordava cedo na rede e fica deitadinho ao meu lado esperando eu levantar também, ficava sentado no meu colo enquanto transcrevia dados etc. Mas eu não gostava que ele se deitasse sujo na minha rede. Geralmente, quando ele tinha sono durante a tarde, depois de brincar na terra, subir em árvores, eu dava banho nele e o fazia dormir na minha rede. Certo dia, ele se rebelou e não quis tomar banho antes de dormir. Cutucava-me para eu pegá-lo e corria em direção a uma plantação de mandioca, localizada nas imediações da aldeia. Eu corria atrás dele e assim iniciamos uma brincadeira. Outras pessoas, inclusive K2, observavam o evento. Riam e se divertiam com a brincadeira. Entretanto, lembrei-me de que teria de me encontrar com um informante. Então resolvi dar banho em Namĩ logo, pois de qualquer forma ele iria dormir na minha rede. Parei de correr atrás dele e o chamei: 
nami, e-xat $\quad x e=\varnothing-p y r i$
nami, 2sg.IMP-VIR $1 s g . I I=R$-POS
'Namĩ, venha cá' (lit: 'venha perto de mim')

E quanto mais eu o chamava mais ele corria e ria. Parei e disse:

$$
\begin{aligned}
& \text { * namĩ a-pyyk ekwe ne-mook-a } \\
& \text { namĩ 1sg.I-pegar F.IMI 2sg.III-banhar-GER } \\
& \text { Namĩ, eu vou te pegar para te banhar' }
\end{aligned}
$$

Imediatamente todos pararam de rir, e K2, de forma séria e tom de voz bravo, chamou K1. Não foi preciso sequer mais uma só palavra, para que o menino estivesse ao lado da mãe. Nesse momento, as pessoas foram se dissipando, e mãe e filho foram para casa. Eu fiquei sem entender o que havia ocorrido. Meio triste fui até em casa, peguei meu material e fui trabalhar com o informante. Ninguém me disse nada, e observei que Namĩ estava deitado em sua rede.

Quando retornei, todos estavam com o semblante sério, menos $K 1$, que correu para os meus braços. Contudo, K2 o levou para longe de mim. Ao sair de casa disse a ele com um sorriso:

$$
\begin{array}{lcc}
\text { we-xãok-pãw-ire } & \text { ekwe } & \tilde{a} \text {-xãr ne=ø-pyri } \\
\text { 1sg.III-banhar-COM-CONS } & \text { F.IMI } & \text { 1sg.I-vir } 2 s g . I I=R-P O S \\
\text { "depois que }
\end{array}
$$

Quando retornei do banho $K 2$ me disse: 'Não tem jeito, Namĩ gosta de você. Ele quer ficar com você. Chorou muito porque tirei ele de você'. E completou: 'Você não pode falar Tapirapé daquele jeito errado. Todo mundo fica muito triste e com vergonha para você. Muita vergonha para você. Você tem cabeça boa e tá aprendendo Tapirapé direitinho' E soprando no meu ouvido, repetiu a seguinte sentença:

$$
\begin{aligned}
& \text { namĩ ara-pyyk ekwe ne-mook-a } \\
& \text { namĩ 2sg.IV-pegar f.imi 2sg.III-banhar-ger } \\
& \text { 'Namĩ, eu vou te pegar para te banhar' (lit: 'Namĩ, você será pego } \\
& \text { por mim e banhado') }
\end{aligned}
$$

K2 ainda continuou soprando frases no meu ouvido para eu não envergonhar mais ninguém até a hora em todos fomos dormir. 
Como se pode notar, a sentença correta, "soprada" no ouvido de WNP, inclui o prefixo \{ara-\} da série IV. Argumentamos que essa configuração, gramaticalizada na língua, está ligada a fatores pragmáticos e semânticos que estabelecem regras de polidez na zona intralocutiva. Se alguém, por algum motivo, utiliza os prefixos de primeira pessoa da série I na situação em que $(1 \rightarrow 2)$, marcando o agente na posição de sujeito ao invés de usar os prefixos \{ara- $\}$ e \{ãpa\}, como fez a pesquisadora, afeta diretamente as regras de polidez da língua, gerando tensão entre os participantes.

Mesmo sendo a hierarquia de pessoa um fenômeno comum a outras línguas do tronco, que, de acordo com Monserrat \& Facó Soares (1983), pode ser reconstruída para o Proto-Tupí, as 17 línguas estudadas por essas autoras apresentam diferentes funcionamento para as pessoas intralocutivas. Segundo Magalhães (2007), por exemplo, a hierarquia de referência no Guajá (Tupí-Guaraní) apresenta uma estrutura diferente da do Tapirapé, pois se observa um nivelamento entre as pessoas intralocutivas $(1=2)$ na configuração $(1 \rightarrow 2)$.

Apesar de o Tapirapé demonstrar características similares a outras línguas da família Tupí-Guaraní, observa-se que em muitas delas não se verifica a ocorrência de prefixos cognatos aos prefixos \{ãpa- $\}$ e \{ara-\} do Tapirapé. Os prefixos da Série IV são usados exclusivamente na configuração $(1 \rightarrow 2)$, que deve marcar a proeminência da segunda pessoa sobre a primeira por meio da inserção do morfema que indica (2>1). Nossa hipótese é a de que a utilização desses prefixos indica uma atitude pragmática/semântica que se gramaticalizou em um tempo remoto, mas que se mantém como uma forte característica da polidez, tenazmente produtiva. Qualquer violação de sua estrutura, além de constituir erro gramatical, acarreta conflitos gerados pela impolidez, constituindo, portanto, erro de ordem gramatical e pragmática.

\section{Considerações finais: perspectivas}

Como vimos, o influente modelo de B\&L (1987[1978]) é alvo de frequentes reformulações (c.f. a versão relativizada de O'Driscoll 
(1996) das noções de face negativa e face positiva) e críticas (c.f. as indagações no que tange à possibilidade de o modelo poder ser aplicado universalmente, feitas por Watts (2005) e outros) ${ }^{21}$. Vários autores, em estudos atuais (c.f. Bargiella-Chiappini, 2002; O'Driscoll, 2008; Kádár, 2009), têm se debruçado sobre problemas de ordem teórica relacionadas ao tema. O’Driscoll $(2008,2010)$, por exemplo, levanta questões relacionadas à difusão, muitas vezes negligente, da noção de face: (i) a partir de quê se constroi a face? Quais seriam as contribuições das necessidades pessoais, da reputação pessoal, da cultura e da situação? (ii) de quê se constroi a face? As respostas podem variar de um conjunto específico e limitado de aspectos (como em B\&L, em que são tomados apenas dois: a face positiva e a face negativa), a um vasto número deles; (iii) como é possível distinguir a face de outras maneiras de se referir a traços individuais como a imagem que o indivíduo tem de si mesmo, sua auto-estima, personalidade, identidade e reputação?

É nossa intenção ampliar a discussão aqui proposta, tendo em vista que os conceitos de face e (im)polidez têm evoluído no sentido de não mais estarem restritos ao estudo das estratégias de mitigação de atos ameaçadores da face. Faz-se necessária, portanto, a coleta de um número maior de dados e, principalmente, de sequências inteiras, como a apresentada em 3.3, que nos permitam investigar de que maneira são negociadas as questões de (im)polidez. A próxima etapa de nossa pesquisa é verificar de que modo os tapirapé manifestam a impolidez, já que sentenças do tipo $(1>2)$ quando $(1 \rightarrow 2)$, conforme visto no excerto em 3.3 , não fazem parte da gramática de sua língua.

\section{Referências bibliográficas}

Bargiella-Chiappini, F. Face and Politeness: new (insights) for old (concepts). Journal of Pragmatics, n. 35, p. 1453-1469, 2003.

21. Ver Vicente (2010) para uma relação mais detalhada de críticos ao modelo de B \& L. 
Benveniste, É. Problemas de Lingüística Geral 1. $3^{\mathrm{a}}$ ed., Campinas: Pontes, pp. 247-259, 1991.

Brown, P. \& Levinson, S. Politeness: some universals in language usage. Cambridge: Cambridge University Press, 1987[1978].

Foley, W. Inherent referentiality and language typology. Canberra, Australian National University, 1976.

Goffman, E. The Presentation of Self in Everyday Life. New York: Anchor Books, 1959.

Jensen, C. “Tupí-Guaranî”. In: Dixon, R. M. W. \& Aikhenvald, A. Y. The Amazonian Languages. Cambridge: Cambridge University Press, pp. 25- 63, 1999.

Kádár, D. Of Concepts and Terms: a self-reflexive exercise. (Ms.) Department of Oriental Studies, Research Institute for Linguistics, Hungarian Academy of Sciences, 2009.

Magalhães, M. M. Sobre a Morfologia e a Sintaxe da Língua Guajá. Tese de doutorado. Brasília: UnB, 2008.

Monserrat, R. \& Facó Soares, M. "Hierarquia Referencial em Línguas Tupí”. In Simões, A. M. \& Reis, C. A. (orgs.). Ensaios de Linguística. Cadernos de Linguística e Teoria da Literatura, vol. 9. Belo Horizonte: UFMG, pp. 164187, 1983.

O'Driscoll, J. About Face: a defense and elaboration of universal dualism. Journal of Pragmatics, n. 25, p. 1-32, 1996.

. Some Problems with the Concept of Face: a review. Comunicação apresentada no 4th International Symposium on Politeness 'East meets West', Budapeste, Hungria, 2008.

. Some Issues with the Concept of Face: when, what, how and how much? Ms., University of Huddersfield, 2010.

Praça, W. Morfossintaxe da Língua Tapirapé. Tese de doutorado inédita. Brasília: UnB, 2007.

Roberts, I. Comparative Syntax. Londres: Arnold, 1997.

Vicente, H. \& Ramalho, F. Uma Visão Pragmática de Crenças de Alunos sobre o Ato de Errar. Revista Brasileira de Linguística Aplicada, v. 9, n. 1, p. 225-243, 2009. 
Vicente, H. As Noções Pragmáticas de Polidez e Face e Sua Contribuição para o Estudo de Crenças. In: Silva, K. A. (Org.). Crenças, Discursos e Linguagem. Campinas: Pontes, 2010.

Watts, R. Linguistic Politeness Research: Quo vadis? In: Watts, R.; Ide, S.; Ehlich, K. Politeness in Language. The Hague: Mouton de Gruyter, 2005. Yule, G. Pragmatics. Oxford: Oxford University Press, 1996.

Zwicky, A. M. On Clitics. Bloomington: IULC, 1977.

Recebido em: julho de 2010 Aprovado em: outubro de 2010 wlkr@uol.com.br helenagv@terra.com.br 